\title{
Tuition fees, self-esteem and social heterogeneity
}

\author{
David Flacher* and Hugo Harari-Kermadec ${ }^{\dagger}$
}

\begin{abstract}
Modelling students' behaviour in relation to tuition fees is a complex task since students' "talent" is not common knowledge. Students observe a private noisy signal of their abilities, while university receives noisy information based on the quantitative and qualitative data provided by university applicants. In this article, we add the heterogeneity of the population to this model: we assume that this heterogeneity means that the perception of skills among a part of the population is biased and underestimates the capabilities of its members to succeed in the higher education system. Our conclusions differ from those derived in the literature and show in particular that the optimal tuition fees for a given number of students are lower than those obtained for a homogeneous population.
\end{abstract}

\section{Introduction}

With the exceptions of the United States education system and business schools, tuition fees have been affordable for most developed country populations. However, raising the levels of fees for higher education is being practised in several countries including Australia and the United Kingdom and is being considered in western Europe more generally. It is being argued that increasing fee levels provides a better selection procedure, if certain conditions are fulfilled (see e.g. Gary-Bobo and Trannoy [2008]). The main conditions are basically:

- the existence of imperfect and asymmetric information (students observe a private noisy signal about their abilities and the university receives noisy information on applicants' abilities);

- the absence of student loan imperfections, which should "guarantee" that good enough students from low income families will be able to enter higher education by borrowing the money required to cover their tuition fees, and repaying it when they are employed.

*Université Paris 13, CEPN - CNRS. e-mail address: david@flacher.fr. Postal address: 30 rue de la Butte aux Cailles - 75013 Paris - FRANCE

${ }^{\dagger}$ ENS Cachan - Université Paris 1, SAMM. e-mail address : hugo.harari@ens-cachan.fr 
Imperfections and asymmetric information lead to adverse selection. This can be reduced by the application of higher tuition fees which discourage inappropriate students from applying to universities ${ }^{1}$. In such a model, the level of tuition fees should be particularly high since the university's information about the ability of its potential students is low. Tuition fees might even be the best way to select students in the presence of "one-sided asymmetric information" (i.e. if students' private information is not shared with the university but the information available to the university (examination results) is common knowledge $)^{2}$.

Relying on this simple framework ${ }^{3}$, several normative works (Gary-Bobo and Trannoy [2005a], Gregoir [2008]) have tried to determine the best way to select students for higher education and to finance educational institutions and have proposed "ranges" of fees and student loan arrangements.

The stakes are high: following the proposals and recommendations in the works referred to above would result in a deep transformation of the economic, social, cultural and institutional basis of current education systems and would have consequences that would require detailed analysis. Before any change in policy, the robustness of these results should be thoroughly checked. Our research adds further to the debate by arguing that the heterogeneity of the population also affects individuals' perceptions of their talents.

This article is organised as follows: Section 1 discusses two of the main assumptions made in the literature: "homogeneous information" and "absence of borrowing constraints". This is our justification for including population heterogeneity. Section 2 shows that some of the previous results are not robust to its inclusion. Section 3 broadens the discussion on tuition fees and identifies some perspectives for further research.

\section{Modelling students' behaviour towards tuition fees: information and borrowing constraints}

\subsection{Imperfect and asymmetric information}

The first issue we need to consider when analysing students' behaviour in relation to tuition fees is the imperfect and asymmetric perceptions of their own talent : individuals' and universities receive «noisy » information on students' abilities. The students' information is based on personal perception ; the universities' information is based on examination results and qualitative assessments. We can model this asymmetric information. The asymmetry will be "bilateral"

\footnotetext{
"Inappropriate" students are those with low level abilities such that the cost of higher education would be higher than the expected gains from this education (i.e. higher wages net of university costs).

${ }^{2}$ In this case, applicants know and use all the information on them that the university owns. Since the gains in terms of the wages due to education increase both individual and social welfare, it will be socially optimal to let potential applicants decide whether to apply or not, given the optimal tuition fees established in the model.

${ }^{3}$ This research is described in a Working Paper: Gary-Bobo and Trannoy [2005b].
} 
if the university is not privy to the information owned by the student on his or her ability and if the student has imperfect knowledge about the information that the university owns. If the university's information is common knowledge then the asymmetry is "one-sided".

These asymmetries are realistic and can explain the opportunistic behaviour of university applicants. Gary-Bobo and Trannoy [2008]'s model overcomes these asymmetries by joint implementation of tuition fees and examinations. Tuition fees appear to be particularly important in the higher education selection process because the applicant owns accurate information about his or her talent (as self-selection improves), because it is not easy for the university to assess the student's ability (examinations and tuition fees become less substitutable) and because of "one-sided" information asymmetry (university's information is common knowledge $)^{4}$.

However, this does not take into account that students' behaviours and beliefs depend also on their social environment. The importance of social environment has been highlighted in the literature: individuals with the same basic talents differ in their abilities to comply with the social codes of examinations and in their perception of their own abilities. Students from socially and/or culturally privileged backgrounds tend to estimate more precisely (or to overestimate) their talent, while the reverse is true of students from disadvantaged families ${ }^{5}$.

Bourdieu [1974] claims that "Adolescents will behave [...] in order to achieve what they perceive to be fact: when one comes from a disadvantaged background, he does not enter to university. [...] The abilities required to 'choose' the best objective strategy (e.g. a financial investment, a school, a career) are very unequally distributed. They vary almost in proportion to the power that depends on the success of the strategy. [...] Thus, even at a high level of curriculum and despite the effects of over-selection, we find that students have fairly modest academic ambitions (and low results expectations) and modest career expectations because they belong to groups with the most limited education opportunities." (p. 6, 8 and 9).

This "bad academic investment" can be explained by the poor information owned by certain social classes concerning educational opportunities ${ }^{6}$, by the lack of alternative opportunities in the case of failure, for individuals with limited social capital, or by lack of knowledge about the positions open to those with better education. Investment into education is a reflection also of the desire of the privileged classes to maximise "symbolic" the returns from education beyond

\footnotetext{
${ }^{4}$ See footnote $n^{\circ} 2$.

${ }^{5}$ The bias stemming from the social or cultural environment in terms of the ability to sit and pass examinations is not addressed in the model introduced in the Section 2 ; we limit our analysis to the bias related to individual perceptions of talent. However, these effects are self-reinforcing and are referred to in the discussion of our results.

${ }^{6}$ According to Bourdieu [1974], p.13, "This gap can lead to inappropriate strategies, because these strategies may be anachronistic: employees whose careers were curtailed because they did not achieve the baccalaureate will often make efforts to ensure that their children pass this examination despite this qualification no longer representing the same negative and positive functions [..."”.
} 
maximisation of economic returns ${ }^{7}$.

A similar view is expressed in Boudon $[1974,1994]$ and has been subsequently theorised and theoretically tested. Sullivan [2006], for instance, shows empirically that "both the social background and gender of students affect their perception of their own abilities" (p.1). Similarly Micklewright [1989], controlling for ability and school type, shows that family background is a key variable explaining the proportion of children who terminates full-time education at the age of 16 (even when ability and school type are controlled for). Hearn [1991] shows that students from lower income families are likely to attend less selective institutions regardless of their academic ability. Sullivan [2006] contributes by studying student's motivations (subjective beliefs and attitudes) supporting the existence of an unfavourable bias in the perception of abilities among those in the lower social classes. This result is consistent with the widespread and systematic cognitive errors suggested by social psychologists ${ }^{8}$.

The decisions made by students' from lower and upper social backgrounds is also considered in the "relative risk aversion" (RRA) theory ${ }^{9}$, based on the work of Boudon. According to Boudon, two types of effects of social background on education decisions can be distinguished. The primary effects are related to the impact on students' cognitive abilities (mainly based on the available economic and cultural resources); the secondary effects are related to the impact of social background for people characterised by similar cognitive ability. Following Boudon, RRA theory states that these secondary effects are explained by the difference in utility gain from the same educational choice: the willingness to avoid social downward mobility would be higher than the desire to achieve upward mobility. Ambition therefore is relative to the individual's social starting point: "Children from higher social origins will then stay in the educational system longer than their lower class counterparts with equal talents" ${ }^{10}$. This is supported empirically by the work of Holm and Jaeger [2008] and others ${ }^{11}$, which shows that "relative risk aversion [...] strongly affects schooling ambitions"12.

Recent empirical work confirms that there is a strong correlation between an individual's social characteristics and academic perspectives ${ }^{13}$. This is consistent with the hypothesis of biased "information" among various social groups

\footnotetext{
${ }^{7}$ Bourdieu [1974], p.13.

${ }^{8}$ See, e.g., Kahneman et al. [1982] and Boudon [1994]. Also similar results than that of Sullivan [2006] has been found by Caillé and O'Prey [2005], p.50: They show that students assess their ability with a positive bias when they come from an upper social background and a negative bias when they come from a lower social background.Gambetta [1987] introduces another mechanism in which normative pressure increases individual resistance to the temptation to abandon school after a failure (p.173).

${ }^{9}$ See Breen and Goldthorpe [1997] or Holm and Jaeger [2008].

${ }^{10}$ Van de Werfhorst and Hofstede [2007], p.392.

${ }^{11} \mathrm{~A}$ large review of empirical articles on RRA theory is available in Holm and Jaeger [2008].

${ }^{12}$ Van de Werfhorst and Hofstede [2007], p.391. This holds despite work that suggests that high school students may be overly ambitious (see Baird et al. [2008] for the case of US students) or that "the influence of social origins decreases progressively at educational branching points" (Schneider [2008], p.511).

${ }^{13}$ See, e.g., Hearn [1984] andBaird et al. [2008].
} 
about their ability to "succeed": Finnie et al. [2005] using Canadian data show that family characteristics (education level of parents, family type, ethnicity, place of residence) have significant effects on university registration. Haveman and Smeeding [2006] suggest that "Sharply rising college prices during the 1980s and 1990s, together with the growing inequality of family income, have raised the cost of attending college far more for low-income students than for wellto-do students" (p.125). There is also an abundant literature highlighting that "Children who grow up in a poor or low income family tend to have lower educational and labour market attainments than children from more affluent families [...]" (see Haveman and Wolfe [1995], p.1870). Research conducted in the 1970s shows that up to "one third of the measured role of education in attainments reflects the influence of family background [...]" (p.1841). More recent work using more accurate in-depth empirical techniques estimates a much stronger $\operatorname{link}^{14}$.

As Haveman and Wolfe [1995] point out, sociological and economic results are consistent despite relying on different theoretical and methodological backgrounds ${ }^{15}$. As they also stress, the psychology literature emphasises the role of certain family events (divorce, parental unemployment...) and parents' psychological resources.

For all these reasons, it seems relevant and more realistic to take account of heterogeneity in the quality of individuals' information on their personal talent.

\subsection{Borrowing constraints}

Another important issue is related to the effect of borrowing constraints on individuals' behaviour in the presence of tuition fees. Indeed, far from being independent of perceptions of information it may reinforce the discussion above. Capital market imperfections and, more specifically, information asymmetries are considered by some to be unfavourable for talented but financially poor students ${ }^{16}$ while some authors consider these asymmetries to be more favourable. Hidalgo Cabrillana [2009], for instance, suggests that capital market imperfections could have positive impacts on talented but less well off students if there

\footnotetext{
14"All of these studies find correlations approximately twice as high as those of the earlier studies, in part as a result of the errors in variables and life-cycle problems affecting the earlier studies. Their findings call into question Becker's conclusion in 1988 that "low earnings as well as high earnings are not strongly transmitted from fathers to sons" (p. 10)" (Haveman and Wolfe [1995], p.1843).

15“The Socialisation/Role Model Perspective [...] stresses the potentially important effect of role models and socialisation (adults or peers to whom children or adolescents relate and who set norms of behaviour and achievement to which they aspire) during childhood and adolescent years on achievements as young adults. [...] While the channels of transmission in this framework are quite different from those emphasised by economists, the implications of this perspective are consistent with the economist's with respect to the potential effects of parental education, labour supply, and fertility choices on children's attainments" (Haveman and Wolfe [1995], p.1834-1835).

${ }^{16}$ E.g.Aghion and Bolton [1997] argue that capital market imperfections mean that poor people have fewer opportunities to invest in their projects. See also the literature on the impact of information asymmetries on intergenerational mobility and income distribution (reviewed in Hidalgo Cabrillana, 2009).
} 
is a menu of borrowing contracts. The banks have imperfect information on students' ability and may construct such a borrowing menu of contacts in order to induce student self-selection. In this case, Hidalgo Cabrillana [2009]shows that very able students from poor families are more likely to invest in education than in the presence of full information. In her model, such students over-invest which allows them to climb the economic ladder (and this is reinforced by the fact that probability success depends on the level of investment in human capital). However, this type of model considers that students have perfect knowledge about their capacities. In the case that the bias highlighted in Section 1.1 applies, Hidalgo Cabrillana [2009] results are weakened since students will be unable carefully to self-select. In this context, the roles of the banks and the universities in our framework are similar: both induce students to reveal private information through their human capital investment decisions (the former using a menu of contracts and the latter through tuition fees).

Although the absence of borrowing constraints is neither a sufficient nor a necessary condition to solve the problems of intergenerational mobility and optimal attendance in the education system, this condition is widely assumed in the literature in order to avoid the problem of funding of education (shortterm constraint) in the case of "talented" students from lower socioeconomic backgrounds. It implies that a loan system (usually at low or no interest rates) is available to all and introduces "pay-as-you-go" based on reimbursement of fees once the individual enters a profession.

However, this assumed that, in the decision to enter higher education, belonging to a family able to finance the educational costs and benefiting from the "right" to borrow for this purpose are equivalent. This means, in turn, that the decision to attend university depends only on the difference between the expected wage rate gain through higher education (net of tuition fees) and wage rate for unskilled workers. This difference depends not on the student's social environment but on his or her basic talent, randomly distributed within the population, an assumption that we retain.

The reality and the strength of the borrowing constraint are discussed in the literature in relation to other key variables. Using Canadian data, Frenette (2007) finds that the borrowing constraint is not very important. Only $12 \%$ of the gap in university attendance between students with parents in the highest income quartile and parents in the lowest income quartile is related to financial constraints (Frenette [2007]). Parents' educational level, their expectations and the quality of the available secondary schooling have more explanatory power. These results are consistent also with those in Carneiro and Heckman [2002] and Keane and Wolpin [2001]. The latter uses a counter-factual methodology to show that the elimination of the (still strong) borrowing constraint has no significant effect on university enrolment and that university registration and academic success are explained by other types of transfers between parents and children (such as tutoring) than financial constraints.

In contrast, there is research that emphasises the impact of the debt burden on the decision to apply to a university, to choose a particular field of education and to favour a type of occupation (e.g. in public administration or the private 
sector). Relying on empirical and experimental studies of students, Field [2009] show that even perfect access to finance may be insufficient to avoid the distortions related to the debt burden: if borrowing behaviours and the reactions to the debt burden are not rational then career choices will be distorted in favour of lucrative jobs, to the detriment of jobs that might be socially useful.

Differences in tuition fees - in terms level and growth (see Cameron and Heckman [2001]) - have an impact on the choice of a university (particularly in terms of public or private). There is also some evidence that although borrowing constraints may be low, some social groups are more sensitive than others. Following Plug and Vijverberg [2005]: "high-ability children in low-income families face binding credit constraints that society may wish to relieve" (p.1). This is echoed in Frenette [2005] who demonstrates the highly negative impact of an unexpected increase in tuition fees in Ontario on the chances of middle class students continuing their studies.

In a case analysis of British data, Callender [2006] argues that the "evidence suggests that debt deters university entry among certain groups of would-be students. Debt aversion has the greatest impact on prospective students from low income families, the very group the government most wants to attract into higher education. [...] However, student debt has increased rapidly as a direct result of the 1998 Teaching and Higher Education Act, and is set to rise yet further following the introduction of variable tuition fees in 2006. So overall, the actual student funding system may act as a disincentive and obstacle to access and participation, especially for those from low income families who are most reliant on student loans and leave university with the highest debts. [...] The 1998 reforms of student funding, therefore, have led to a rise in the financial burden of higher education particularly for the poorest. With that rise, these students encounter increases in the financial and personal risks associated with going to university. The most disadvantaged students, and the very focus of widening participation policies, experience the greatest risks, hardship and financial pressures, all of which affect their chances of success and their ability to participate fully in university life" (p.126).

Although they do not specify the origins of the phenomena observed, Brodaty et al. [2009] empirical study stresses the different behaviour of individuals from the better educated classes and others. The authors show that students coming from the best educated families (the "sons of professionals") are paradoxically more risk averse since they have more to loose than those from less well educated families. However, these differences are not sufficient to offset other effects ${ }^{17}$ that induce higher private returns from investment in education for children from the best educated social classes (and lower working class participation in higher education). Higher fees would appear to be relatively negative in terms of university attendance by the working class population ${ }^{18}$.

\footnotetext{
${ }^{17}$ According to the authors, these include "unobservable inter-generational transfers" (explained in part in the other articles cited above).

18“Simulations also show that the impact of higher education costs (i.e. tuition fees and other costs) on higher education enrolment is important, affecting more the students whose parents are less educated" (Brodaty et al. [2009], p.28).
} 
These results on the relation between social class and the propensity to enrol at a university are in line with those in the sociology literature (e.g. Bourdieu [1974]). With the exception of the most privileged classes who feel sufficiently secure to undertake a lengthy and difficult education, the authors underline that the middle classes most often restrict their education investment in order to secure the returns expected from further education rather than to take a risk ${ }^{19}$. This leaves the disadvantaged social classes generally (self-)excluded from higher education (and particularly the most prestigious and risky courses).

It seems reasonable to suggest, therefore, that students from disadvantaged backgrounds are more reluctant to incur debt than students from privileged backgrounds who often do not need to borrow and who enjoy domestic security. Thus, the former will take on debt only in the case of very high self-assessment of their talent, while the latter will be much more relaxed about being in debt.

This implies that provision of access to credit in order to finance studies is not sufficient to enable access to university courses: "The rights given by law are only the explicit, guaranteed and legitimate form of this set of appropriate opportunities, of monopolised possibles, by which the current power struggles launch themselves into the future, controlling for their part the current talents. [Thus the dispossessed classes] tend to apportion their investment in education in functions of guaranteed profits, thereby anticipating the systemic risks involved" ${ }^{\prime 20}$. The gap between those two extremes can be compared to Sen [1992]'s analysis of "capability".

The assumption of rationality is particularly inappropriate for the analysis of educational investment since rationality is "the output of a particular economic condition that defines possession of the economic and cultural capital required to efficiently capture the 'potential opportunities' which seemingly are available to everyone, but in reality are available only to those with the abilities to exploit them"21. In this context and despite the reduced constraint on borrowing, the relatively strong impact of rising tuition fees on the decision to continue studies (and on career choices) tends to support the assumption that privileged and disadvantaged populations do not have the same perceptions of their "abilities (to succeed), i.e. of their talents.

\subsection{A new assumption}

The above demonstrates that the assumptions of the existence of imperfect information and the absence of borrowing constraints are not independent of the economic, social and cultural context of the individual: in both cases there is bias. The bias generally favours the socially and culturally privileged classes

\footnotetext{
${ }^{19}$ Bourdieu [1974], p.14. Bourdieu also notes that the educational system is built "at every crossroads of the curriculum", which he describes as the "stockholder approach" of the middle class (the "petits bourgeois" class and the "speculation in order to maximise profit" approach of the privileged classes: "The most risky courses of studies, which are often the most prestigious, always have a less prestigious alternative for those with insufficient economic, cultural or social capital to be able to risk 'losing everything in the attempt to win everything'.)".

${ }^{20}$ Bourdieu [1974], p.15-16.

${ }^{21}$ Bourdieu [1974], p.11.
} 
and is negative for the disadvantaged class. We can (at least partially) model this bias. Based on the hypothesis that talents are distributed randomly among the population, we can introduce a bias in relation to the individuals' perception of their talent. Rather than modelling this perception using a common zero mean random variable, we distinguish two groups within the population:

- a group of disadvantaged individuals who perceive their talent negatively and have a reduced expectation of expected returns from investment in education, and a possibly higher risk or debt burden aversion ${ }^{22}$;

- a group of "privileged" individuals who perceive their talent with a positive or zero bias. For simplicity, we assume that this class of individuals has no perception bias.

In the next section, we analyse the impact of this assumption on the results in Gary-Bobo and Trannoy [2008].

\section{The proposed model}

\subsection{The population}

We follow Gary-Bobo and Trannoy [2008]'s notations and framework in introducing our assumption. Workers fall into two categories: skilled, that is university graduates, and unskilled, who did not go on to higher education. Unskilled workers' wages are at a constant rate $w_{0}$. Students pay tuition charges $p$ during the first period (and receive no wages): they become skilled workers on completing their studies.

In this paper, we consider only a monopolistic higher education system with one university and one level of tuition fees and, therefore, one type of skilled worker. A more detailed model might investigate a matching between potential students with diverse abilities and different universities. This could be modelled using nested binaries alternatives: a potential student would compare the cheapest (lowest fees) university with skipping higher education. If schooling is seen as worthwhile, the second cheapest university is compared with the first, and so on, until the student's talent additional premium does not compensate for the additional tuition fees. Such a model would be equivalent to a succession of binaries models where the premia are considered as premium differences. For simplicity, we consider the only case where students face a unique binary choice.

The wage received by a skilled worker depends on a common skilled premium $K(q)$ (earned through education), where $q$ is the number of graduates ${ }^{23}$. It

\footnotetext{
${ }^{22}$ Note that aversion to debt depends on the level of risk aversion and the expected returns from investment in education. Note also that, in some way, our model indirectly captures the difficulties faced by the most disadvantaged population, based on their specific borrowing constraints.

${ }^{23}$ The skilled premium at first sight might be seen as a decreasing function of the number of graduates (see, e.g., Lorel [2009]). As underlined by Gary-Bobo and Trannoy [2008], the function $K$ can be increasing or decreasing: skilled workers can exist concurrently in the
} 
depends also on the individual's talent (or "ability"), modelled by a random variable $\tilde{\theta}$. Taking into account a constant preference for present $r$, individual infinite horizon inter-temporal utilities can be written as:

- for an unskilled worker: $u_{0}=w_{0}+\frac{\ln \left(w_{0}\right)}{r}$

- for a skilled worker: $u_{1}=-p+\frac{\ln \left(w_{0}\right)+\tilde{\theta}+K(q)}{r}$

Let $\theta=\frac{\tilde{\theta}}{r}$ and $\Delta(q)=\frac{K(q)}{r}$. Then the difference between utilities is:

$$
u_{1}-u_{0}=\Delta(q)+\theta-p-w_{0}
$$

where $\theta$ is assumed to be a Gaussian with zero mean and variance $\sigma_{\theta}^{2}$. Information on $\theta$ is assumed to be incomplete and asymmetric. The university observes the tests results (and other qualitative information) which provide another estimation of ability:

$$
z=\theta+\nu, \text { with } \nu \sim \mathcal{N}\left(0, \sigma_{\nu}\right)
$$

The university sets an admission standard $z_{0}$. If $z<z_{0}$ which must be achieved for an individual to be allowed to apply. Otherwise, potential students choose to register or not, and dispose of two information sources to estimate their $\theta$ : their private signal $s$, which we model below, and the fact that $z \geq z_{0}$.

Potential students apply for higher education if their expected utility as skilled worker $\left(u_{1}\right)$ is higher than the utility of unskilled workers $\left(u_{0}\right)$ :

$$
\begin{gathered}
\mathbb{E}\left[u_{1} \mid s, z \geq z_{0}\right]=\mathbb{E}\left[\theta \mid s, z \geq z_{0}\right]-p+\frac{\ln \left(w_{0}\right)}{r}+\Delta(q) \geq u_{0} \\
\Leftrightarrow \mathbb{E}\left[\theta \mid s, z \geq z_{0}\right] \geq p+w_{0}-\Delta(q)
\end{gathered}
$$

Let $\hat{\theta}=\mathbb{E}\left[\theta \mid s, z \geq z_{0}\right]$ : for a potential student, it is the expectation of their own ability.

Let $\theta_{0}=p+w_{0}-\Delta(q)$ : this is the minimum expected ability below which applying for higher education is not worthwhile.

Relying on the arguments discussed in Section 1.3 and assuming abilities to be random $\left(\theta \sim \mathcal{N}\left(0, \sigma_{\theta}\right)\right)$, we introduce population heterogeneity in information perception: the signal $s$ is therefore social group dependent.

In group A individuals, with population $N_{A}$, from "privileged"class, the signal is unbiased:

$$
s_{A}=\theta+\varepsilon, \text { with } \varepsilon \sim \mathcal{N}\left(0, \sigma_{\varepsilon}\right) .
$$

In group B individuals, with population $N_{B}$, from "disadvantaged" class, there is a negatively biased impact on the signal:

$$
s_{B}=\theta-\delta+\varepsilon, \text { with } \varepsilon \sim \mathcal{N}\left(0, \sigma_{\varepsilon}\right) \text { and } \delta>0 .
$$

labour market, meaning their number would have a negative impact on their wages; but by developing a knowledge economy a large number of skilled workers could also increase the high-wage job opportunities. 
For both groups, the university signal is:

$$
z=\theta+\nu, \text { with } \nu \sim \mathcal{N}\left(0, \sigma_{\nu}\right) .
$$

Let $\hat{\theta}_{A}$ and $\hat{\theta}_{B}$ be the values of $\hat{\theta}$ for individuals respectively from groups $A$ and $B$. The higher education opportunity depends on the group and is given by:

$$
\begin{array}{ll}
\hat{\theta}_{A}=\mathbb{E}\left[\theta \mid s_{A}, z \geq z_{0}\right] & \geq \theta_{0} \\
\hat{\theta}_{B}=\mathbb{E}\left[\theta \mid s_{B}, z \geq z_{0}\right] & \geq \theta_{0}
\end{array}
$$

We would emphasise that the bias for group $B$ affects the estimation of $\theta$. Since this is not a conscious bias the estimator of $\theta$ for group $B$ is the same as for group $A$, and is based on $s=\theta+\varepsilon$ and on the correct model $z=\theta+\nu$. The estimator $\hat{\theta}$ can be decomposed as a function of $s$ and $\mathbb{1}_{z \geq z_{0}}$, for any potential student, from whatever group, as follows:

$$
\hat{\theta}=u s+v \mathbb{1}_{z \geq z_{0}}
$$

Consider two potential students with the same abilities $\theta$ and the same noise $\varepsilon$, but from different groups. The individual from group $B$ estimates that it will be less beneficial to apply for higher education since:

$$
\begin{aligned}
\hat{\theta}_{A}-\hat{\theta}_{B} & =u s_{A}+v \mathbb{1}_{z \geq z_{0}}-u s_{B}-v \mathbb{1}_{z \geq z_{0}} \\
& =u \delta>0
\end{aligned}
$$

\section{2 "Philanthropic" university: optimal tuition fees in the presence of bilateral asymmetric information}

To simplify the notations, we set $P_{A}\left(\theta_{0}, z_{0}\right)=\mathbb{P}\left(\hat{\theta}_{A} \geq \theta_{0}, z \geq z_{0}\right)$ to denote the probability that a potential student from group $A$ applies for higher education and $\nu_{A}\left(\theta_{0}, z_{0}\right)=\mathbb{E}\left[\theta \mid \hat{\theta}_{A} \geq \theta_{0}, z \geq z_{0}\right]$ as the conditional expectation of $\theta$ for the resulting skilled worker. The corresponding $\nu_{B}$ and $P_{B}$ for group $B$ are defined similarly.

For a "philanthropic" university, the expected social surplus is given by the sum of individual expected utilities on the population $\left(q=N_{A} P_{A}\left(\theta_{0}, z_{0}\right)+\right.$ $N_{B} P_{B}\left(\theta_{0}, z_{0}\right)$ skilled and $N-q$ unskilled workers) minus the cost $C(q)$ of higher education:

$W=q\left[\Delta(q)-w_{0}\right]+N_{A} P_{A}\left(\theta_{0}, z_{0}\right) \nu_{A}\left(\theta_{0}, z_{0}\right)+N_{B} P_{B}\left(\theta_{0}, z_{0}\right) \nu_{B}\left(\theta_{0}, z_{0}\right)-C(q)+N u_{0}$

This social surplus is maximised with respect to the expected number of students $q$, the admission standard $z_{0}$ and the tuition fees $p$ (or equivalently $\theta_{0}$ ) and under the constraint that $q=N_{A} P_{A}\left(\theta_{0}, z_{0}\right)+N_{B} P_{B}\left(\theta_{0}, z_{0}\right)$. No budgetary constraint is considered in the case of the "philanthropic" university. This means 
that, in some cases, the State might have to subsidise the university and thus might have to find sources of funding ${ }^{24}$.

We start by maximising $W$ with respect to $z_{0}$ and $\theta_{0}$ for a fixed value of $q$. The Lagrangian corresponding to this maximisation is given by:

$$
\begin{aligned}
L=q\left[\Delta(q)-w_{0}\right]+ & q \nu_{A}\left(\theta_{0}, z_{0}\right)+N_{B} P_{B}\left(\theta_{0}, z_{0}\right)\left(\nu_{B}\left(\theta_{0}, z_{0}\right)-\nu_{A}\left(\theta_{0}, z_{0}\right)\right) \\
& -C(q)+N u_{0}+\lambda\left[q-\left(N_{A} P_{A}\left(\theta_{0}, z_{0}\right)+N_{B} P_{B}\left(\theta_{0}, z_{0}\right)\right)\right]
\end{aligned}
$$

To simplify the notation, we use $\partial$ to denote the partial derivative with respect to $\theta_{0}$. The first order condition corresponding to $\theta_{0}$ is written as:

$\partial L=q \partial \nu_{A}+N_{B} \partial P_{B}\left(\nu_{B}-\nu_{A}\right)+N_{B} P_{B}\left(\partial \nu_{B}-\partial \nu_{A}\right)-\lambda\left(N_{A} \partial P_{A}+N_{B} \partial P_{B}\right)=0$.

Since $q=N_{A} P_{A}+N_{B} P_{B}$,

$$
\begin{gathered}
0=\left(N_{A} P_{A}+N_{B} P_{B}\right) \partial \nu_{A}+N_{B} P_{B}\left(\partial \nu_{B}-\partial \nu_{A}\right)+N_{B} \partial P_{B}\left(\nu_{B}-\nu_{A}\right)-\lambda\left(N_{A} \partial P_{A}+N_{B} \partial P_{B}\right) \\
=N_{A} P_{A} \partial \nu_{A}+N_{B} P_{B} \partial \nu_{B}+N_{B} \partial P_{B} \nu_{B}+N_{A} \partial P_{A} \nu_{A}-\left(\nu_{A}+\lambda\right)\left(N_{A} \partial P_{A}+N_{B} \partial P_{B}\right) \\
\lambda=-\nu_{A}+\frac{\partial\left(N_{A} P_{A} \nu_{A}+N_{B} P_{B} \nu_{B}\right)}{\partial\left(N_{A} P_{A}+N_{B} P_{B}\right)}
\end{gathered}
$$

Accordingly, differentiating with respect to $z_{0}$, we obtain:

$$
\lambda=-\nu_{A}+\frac{\partial / \partial z_{0}\left(N_{A} P_{A} \nu_{A}+N_{B} P_{B} \nu_{B}\right)}{\partial / \partial z_{0}\left(N_{A} P_{A}+N_{B} P_{B}\right)}
$$

To simplify the notations, we define the weighted expected ability $q \nu$ and weighted probability of applying $N P$ as:

$$
\begin{aligned}
q \nu & =N_{A} P_{A}\left(\theta_{0}, z_{0}\right) \nu_{A}\left(\theta_{0}, z_{0}\right)+N_{B} P_{B}\left(\theta_{0}, z_{0}\right) \nu_{B}\left(\theta_{0}, z_{0}\right) \\
\text { and } N P & =N_{A} P_{A}\left(\theta_{0}, z_{0}\right)+N_{B} P_{B}\left(\theta_{0}, z_{0}\right)
\end{aligned}
$$

then the first order condition can be written as:

$$
\left\{\begin{aligned}
\lambda & =\frac{\partial q \nu / \partial \theta_{0}}{\partial N P / \partial \theta_{0}}-\nu_{A} \\
\lambda & =\frac{\partial q \nu / \partial z_{0}}{\partial N P / \partial z_{0}}-\nu_{A}
\end{aligned}\right.
$$

and we get the tautological equality of the ratio of partial derivatives

$$
\frac{\partial N P / \partial \theta_{0}}{\partial N P / \partial z_{0}}=\frac{\partial q \nu / \partial \theta_{0}}{\partial q \nu / \partial z_{0}}
$$

The maximisation with respect to $q$ gives:

\footnotetext{
${ }^{24}$ Finding resources, the marginal costs of funding and how to raise funding are not addressed in this article.
} 


$$
\frac{\partial L}{\partial q}=q \Delta^{\prime}(q)+\Delta(q)-w_{0}-C^{\prime}(q)+\nu_{A}+\lambda=0
$$

Since $p=\theta_{0}+\Delta(q)-w_{0}$ and using Equation (1) to replace $\lambda$, we find:

$$
\begin{aligned}
0 & =q \Delta^{\prime}(q)+p-\theta_{0}-C^{\prime}(q)+\nu_{A}-\nu_{A}+\frac{\partial\left(N_{A} P_{A} \nu_{A}+N_{B} P_{B} \nu_{B}\right)}{\partial\left(N_{A} P_{A}+N_{B} P_{B}\right)} \\
\text { or } p & =C^{\prime}(q)-q \Delta^{\prime}(q)-\frac{\partial\left(N_{A} P_{A} \nu_{A}+N_{B} P_{B} \nu_{B}\right)}{\partial\left(N_{A} P_{A}+N_{B} P_{B}\right)}+\theta_{0}
\end{aligned}
$$

This yields to (see Appendix B):

$$
\frac{\partial\left(N_{A} P_{A} \nu_{A}+N_{B} P_{B} \nu_{B}\right)}{\partial\left(N_{A} P_{A}+N_{B} P_{B}\right)}=\theta_{0}+\frac{u \delta N_{B} \partial P_{B}}{N_{A} \partial P_{A}+N_{B} \partial P_{B}}
$$

and therefore, at the optimum:

$$
p=C^{\prime}(q)-q \Delta^{\prime}(q)-\frac{u \delta N_{B} \partial P_{B}}{N_{A} \partial P_{A}+N_{B} \partial P_{B}}
$$

Recall that the optimal tuition fees in the case of a homogeneous population derived in Gary-Bobo and Trannoy [2008] are $p_{\text {hom }}^{*}=C^{\prime}(q)-q \Delta^{\prime}(q)$. Therefore, they are reduced by the amount (fraction) that comes from the need to counterbalance the bias of potential students from group $B$. This leads to the following proposition:

Proposition 1. In a "philanthropic" setting, in the presence of population heterogeneity leading to underestimation of abilities among some individuals, optimal tuition fees are lower than those obtained for a homogeneous population $\left(p_{\text {hom }}^{*}\right)$, given the amount of student

$$
p^{*}=\underbrace{C^{\prime}\left(q^{*}\right)-q^{*} \Delta^{\prime}\left(q^{*}\right)}_{p_{\text {hom }}^{*}}-\frac{u \delta N_{B} \partial P_{B}}{N_{A} \partial P_{A}+N_{B} \partial P_{B}} .
$$

Discussion on information structure The effect of heterogeneity increases with the relative weight of group $B$ in the population. It converges to 0 as the group becomes negligible. The effect of heterogeneity increases with $u^{25}$ (i.e.

\footnotetext{
${ }^{25}$ We have $\hat{\theta}=u s+v \mathbb{1}_{z \geq z_{0}}$.

with $u=\sigma_{\theta}^{2} \frac{V\left(\mathbb{1}_{z \geq z_{0}}\right)-\operatorname{Cov}\left(s, \mathbb{1}_{z \geq z_{0}}\right)}{V(s) V\left(\mathbb{1}_{z \geq z_{0}}\right)-\operatorname{Cov}^{2}\left(s, \mathbb{1}_{z \geq z_{0}}\right)}$ and $v=\sigma_{\theta}^{2} \frac{V(s)-\operatorname{Cov}\left(s, \mathbb{1}_{z \geq z_{0}}\right)}{V(s) V\left(\mathbb{1}_{z \geq z_{0}}\right)-\operatorname{Cov}^{2}\left(s, \mathbb{1}_{z \geq z_{0}}\right)}$.

where $V(s)=\sigma_{\theta}^{2}+\sigma_{\varepsilon}^{2}$ is the variance of $s$,

$$
V\left(\mathbb{1}_{z \geq z_{0}}\right)=\mathbb{P}\left(z \geq z_{0}\right)\left(1-\mathbb{P}\left(z \geq z_{0}\right)\right)=\left(1-\Phi\left(\frac{z_{0}}{\sigma_{\theta}^{2}+\sigma_{\nu}^{2}}\right)\right) \Phi\left(\frac{z_{0}}{\sigma_{\theta}^{2}+\sigma_{\nu}^{2}}\right)
$$

is the variance of $\mathbb{1}_{z \geq z_{0}}$ and there covariance is
} 
when potential students, deciding whether or not to apply for higher education, rely on their personal signals $s$ more than the information provided by university examinations $z \geq z_{0}$ ). Therefore, the information given by the test is the only way to counterbalance the psychological bias of group $B$. The bias is "balanced" by the level of success in the test ${ }^{26}$.

In the case that the university has perfect information, i.e. $\sigma_{\nu}=0$ and $z=\theta$, students can make more accurate estimations of their abilities (based on the information they get from the institution). The effect of social bias is reduced and the optimal tuition fee level increases.

In the case that students have perfect information on their abilities, that is $s_{A}=s_{B}=\theta$, signals are not noisy and there is no bias and the population is no longer heterogeneous. This is the case considered in Gary-Bobo and Trannoy [2008] who show that it becomes optimal to select students only though tuition fees (and not through an examination): $z_{0}=-\infty$ ). Self-selection by tuition fees is sufficient since potential students have all the information required. Tuition fees in this case $\left(p_{\text {hom }}^{*}\right)$ are higher than in the case of imperfect information $\left(p_{\text {hom }}^{*}>p^{*}\right)$.

For completeness, we consider also the benchmark case of perfect and symmetric information. In such a case, $s_{A}=s_{B}=z=\theta$. The optimal price covers the marginal costs and students are allowed to study as soon as $\theta \geq$ $p *+w_{0}-\Delta(q)$, that is, the skilled premium (including peer effects) covers both the direct and opportunity costs).

Fees and scholarships Theoretically, tuition fees could be negative (meaning that grants for all talented students would be the socially optimal policy ${ }^{27}$ ). However, we note that this is true not only in our framework: it applies also to a homogeneous population if the social need for skilled workers is sufficiently strong (i.e. for a large marginal common skilled premium $\Delta^{\prime}(q)$ ). Heterogeneity reinforces this mechanism, since a negative social bias affects the candidates for higher education and therefore the production of skilled workers. Nevertheless, we would highlight a potential artefact of the model. Heterogeneity could have been modelled as a positive bias in the signal for group A which then would lead to increased fees to discourage overly ambitious students.

$$
\operatorname{Cov}\left(s, \mathbb{1}_{z \geq z_{0}}\right)=\sigma_{\theta} \iint x \mathbb{1}_{\sigma_{\theta} x+\sigma_{\nu} y \geq z_{0}} \varphi\left(\frac{x}{\sigma_{\theta}}\right) \varphi\left(\frac{y}{\sigma_{\nu}}\right) d x d y
$$

where $\varphi$ is the probability density function of the standard Gaussian distribution and $\Phi$ is its cumulative density function.

${ }^{26}$ Nevertheless, the problem may only be postponed: for the same reasons as led to the introduction of $\delta$, a number of studies (notably in sociology) show the presence of a bias that is negative for the "disadvantaged" group of students. This bias would be based on the "social codes" needed to pass examinations (and $z \geq z_{0}$ therefore is also biased). This demonstrates the need for a major and probably compulsory examination, such as the French "baccalaureate". This issue requires further research.

${ }^{27}$ A policy of widely available grants has been implemented in Sweden. 


\subsection{Rent maximising university: optimal tuition fees in the presence of bilateral asymmetric information}

We consider here the case of a non "philanthropic" university, where university maximises its profits (and not the social utility). Of course, the indirect social benefit obtained will be less than that obtained above ${ }^{28}$.

We maximise the profit function of the university under the constraint $q=$ $N_{A} P_{A}\left(\theta_{0}, z_{0}\right)+N_{B} P_{B}\left(\theta_{0}, z_{0}\right)$. The Lagrangian can be written as follows:

$L=q p-C(q)+\lambda\left(q-N_{A} P_{A}-N_{B} P_{B}\right)=q\left[\theta_{0}+\Delta(q)-w_{0}\right]-C(q)+\lambda\left(q-N_{A} P_{A}-N_{B} P_{B}\right)$

Computing the partial derivative with respect to $q$, we find:

$$
0=\theta_{0}+\Delta(q)+q \Delta^{\prime}(q)-w_{0}-C^{\prime}(q)+\lambda \quad \Leftrightarrow \quad p=C^{\prime}(q)-q \Delta^{\prime}(q)-\lambda .
$$

The derivative with respect to $\theta_{0}$, gives:

$$
0=q-\lambda\left(N_{A} \partial P_{A}+N_{B} \partial P_{B}\right) \quad \Leftrightarrow \quad \lambda=\frac{q}{N_{A} \partial P_{A}+N_{B} \partial P_{B}}
$$

Consider the optimum situation. If the university can attract more students by raising its tuition fees, its utility will be augmented. Therefore, at the optimum, the expected number of students is a decreasing function of $\theta_{0}$ and then $N_{A} \partial P_{A}+N_{B} \partial P_{B}<0$. As $q>0$, we get $\lambda<0$. This leads to the following proposition:

Proposition 2. From a social point of view, tuition fees are sub-optimal, for both groups: they are too high for group A (this result also holds for a homogeneous population) as well as a fortiori for group $B$.

In addition, the optimal admission standard $z_{0}^{*}$ must be set such that it does not impact on the number of students ${ }^{29}$.

\subsection{One-sided asymmetric information}

We now study the case in which the signal of a "philanthropic" university $(z)$ is supposed to be public. In such a case, since $z$ is known, potential students have access to more information to estimate whether higher education will be beneficial. Since in this model social utility and individual utility are varying in the same way through the evolution of the wage, individual choices are similarly socially optimal.

The resulting proposition is similar to the one in section 2.2 .

\footnotetext{
${ }^{28}$ Gary-Bobo and Trannoy [2008] do not model competition between universities. Therefore, the case of a non "philanthropic" university necessarily leads to a sub-optimal situation of monopolistic prices.

${ }^{29}$ Computing the derivative of $L$ with respect to $z_{0}$, we find that at the optimum
}

$$
N_{A} \frac{\partial P_{A}}{\partial z_{0}}+N_{B} \frac{\partial P_{B}}{\partial z_{0}}=0
$$


Proposition 3. In the case of a "philanthropic" university, for a heterogeneous population, if $z$ is public then optimal tuition fees are less than those ( $p_{\text {hom }}^{*}$ ) obtained in the case of an homogeneous population, for a fixed number of students:

$$
p^{*}=\underbrace{C^{\prime}\left(q^{*}\right)-q^{*} \Delta^{\prime}\left(q^{*}\right)}_{p_{\text {hom }}^{*}}-\frac{\alpha \delta N_{B} \partial P_{B}}{N_{A} \partial P_{A}+N_{B} \partial P_{B}},
$$

where $\alpha^{30}$ measures the information on $\theta$ from the personal signal s. Since $z$ is available directly to potential students and not indirectly through $\mathbb{1}_{z>z_{0}}$, the effect discussed in the previous section is reinforced: as information from $z$ increases (i.e. as $\sigma_{\nu}$ decreases with respect to $\sigma_{\varepsilon}$ ), potential students from group $B$ have increased awareness of their talents. In the limit case where the test brings complete information on talent, the effect of the psychological bias vanishes $(\alpha=0)$. Optimal tuition fees are then equivalent to the case of a homogeneous population.

\section{Discussion and perspectives}

The literature highlights distorted behaviour among students, depending on their social class: while individuals from some social groups tend to estimate more precisely (or even over-estimate) their abilities and the expected returns from investment in education, other social groups under-estimate these dimensions. Based on this observation and introducing population heterogeneity in the perception of information, we have proposed a more complete model than the currently available one.

We derived that tuition fees are not efficient selection mechanisms for at least two reasons: (i) they tend reject good students that "deserve" to win a university place, but who have underestimated their talents; (ii) they tend to include less talented students from privileged families.

In line with this bias we show that tuition fees should be set below the level that would be fixed for a homogeneous population and the same numbers of students. This is important since previous empirical studies have deduced that most of the population does not face a borrowing constraint when deciding about higher education and that the decision is based on other criteria, primarily social, which are strong enough disincentives for university enrolment and incurring debt. Tuition fees may distort education choices and job opportunities. Low

\footnotetext{
${ }^{30}$ The coefficient $\alpha$ is given by the estimation of $\theta$ from $s$ and $z$ (instead of $s$ and $\mathbb{1}_{z \geq z_{0}}$ ):

with

$$
\bar{\theta}=\mathbb{E}[\theta \mid s, z]=\alpha s+\beta z .
$$$$
\alpha=\sigma_{\theta}^{2} \frac{V(z)-\operatorname{Cov}(s, z)}{V(s) V(z)-\operatorname{Cov}^{2}(s, z)}=\frac{\sigma_{\nu}^{2}}{\sigma_{\nu}^{2} \sigma_{\theta}^{2}+\sigma_{\theta}^{2} \sigma_{\varepsilon}^{2}+\sigma_{\nu}^{2} \sigma_{\varepsilon}^{2}} .
$$

Nevertheless, note that a social rank bias can appear on the test (due to the self-selection for registration to the test or to the possession of the "social codes" needed to succeed in the test). In this case, even an ideal test that perfectly reveals the talents of individuals in group $A$ would not be sufficient to achieve efficient selection.
} 
enough fees appear to be a necessary (although not sufficient) condition for achieving a social optimum. The effect of a constraint on the level of tuition fees is investigated by Easton and Rockerbie [2008]. They propose simple rules to compensate for this constraint based on government subsidies.

However, further research is needed to show that assumptions used in our model and in similar work are sufficiently robust to justify policy recommendations. Our work could be extended to determine the concrete level of tuition fees: should they be higher or lower than currently or should they be abolished? Are they relevant to select students applying to universities? These dimensions depend in particular on the parameters, including the population distribution of the two social groups and the characteristics of these populations.

Another issue is the likely endogenous nature of individuals' abilities, modelled by $\theta$ : if individuals' talents are not only "revealed" but also "developed" by education, in a dynamic perspective, fees should be lower to maintain a low but gifted population in the system whose potential would be improved by further study.

However, staying with exogenously distributed and static abilities, as in Gary-Bobo and Trannoy [2008]'s model, social welfare appears particularly important since the education system integrates stronger incentives for "very talented but financially very poor" students and disincentives for "low talented but well off rich" students. This suggests the need for more research on selection that relies on entrance examinations and for further investigation of possibly more efficient (not linear) pricing mechanisms. These mechanisms could be considered directly (adjusting fees based on certain criteria) or indirectly (grants). Some institutions are investigating systems of fees based on social criteria (parental income) or "merit" since attracting the best students creates positive externalities for both universities (reputation effects) and students (peer effects). The level of tuition fees could also be aligned more to eventual jobs and real incomes after graduation.

Finally, further work could be devoted to exploring other (questionable) justifications for fees in the literature, of incentive, contributory and redistributive ones.

(i) Incentive justifications. The present paper addresses the incentive of tuition fees used to exclude the worst students from higher education and to encourage the most able to enrol at a university. Another incentive is linked to the motivations of students and teachers. Indeed, it would become very expensive for students not to work (or to work only a few hours) while paying high fees for studies. At the same time, teachers would be incited to work harder to answer the stronger demands made by students (and to get the bonuses eventually given to teachers when fees are high). (ii) Contributory justifications. The fees paid by students contribute to financing the running of the universities and thus increase the quality of the education received by allowing the best teachers to be recruited, by funding research, by improving working conditions, etc. (iii) Redistribution would occur since the university intake involves a higher proportion of the upper social classes.

Each of these dimensions requires specific discussion and research to show 
whether, in other forms or for other reasons, the introduction of "significant" tuition fees remains relevant. However, this article shows that fees as a "good" tool of selection needs to be debated. Further work is needed before definitive and normative conclusions can be provided and before "high tuition fee policies" are implemented. This is particularly true in countries claiming to provide "free" education, such as France, since such a policy would lead to a major transformation of national economic, social and cultural patterns of development.

\section{A Expected global talent}

We investigate here expected mean talent in the presence of heterogeneity in order to compare with the situation of a homogeneous population. We assume therefore that heterogeneity is not too important to deal with marginal modifications. Similarly, we assume that $z_{0}$ is fixed at its optimal value for the homogeneous population.

Let $\theta_{0}^{G T}$ and $\theta_{0}^{*}$ be the optimal values obtained for a homogeneous and a heterogeneous population, respectively. Let $q^{G T}$ and $q^{*}$ (assumed to be similar) be the corresponding optimal numbers of students, supposed to be close to each other.

$$
\begin{aligned}
& q \nu_{A}\left(\theta_{0}^{*}, z_{0}\right)+N_{B} P_{B}\left(\nu_{B}\left(\theta_{0}^{*}, z_{0}\right)-\nu_{A}\left(\theta_{0}^{*}, z_{0}\right)\right)-q^{G T} \nu\left(\theta_{0}^{G T}, z_{0}\right) \\
& =q^{*} \mathbb{E}\left[\theta \mid \hat{\theta}_{A} \geq \theta_{0}^{*}, z \geq z_{0}\right]-q^{G T} \mathbb{E}\left[\theta \mid \hat{\theta} \geq \theta_{0}^{G T}, z \geq z_{0}\right] \\
& +N_{B} P_{B}\left(\mathbb{E}\left[\theta \mid \hat{\theta}_{A}-u \delta \geq \theta_{0}^{*}, z \geq z_{0}\right]-\mathbb{E}\left[\theta \mid \hat{\theta}_{A} \geq \theta_{0}^{*}, z \geq z_{0}\right]\right) \\
& =q^{*} \nu_{A}\left(\theta_{0}^{*}, z_{0}\right)-q^{G T} \nu_{A}\left(\theta_{0}^{G T}, z_{0}\right)+N_{B} P_{B}\left(\nu_{A}\left(\theta_{0}^{*}+u \delta, z_{0}\right)-\nu_{A}\left(\theta_{0}^{G T}, z_{0}\right)\right)
\end{aligned}
$$

Notice that

$$
\begin{aligned}
\theta_{0}^{G T}-\theta_{0}^{*} & =p^{G T}-p^{*}+\Delta\left(q^{G T}\right)-\Delta\left(q^{*}\right) \\
& =C^{\prime}\left(q^{G T}\right)-C^{\prime}\left(q^{*}\right)-\left(q^{G T}-q^{*}\right) \Delta^{\prime}\left(q^{G T}\right)+\frac{u \delta N_{B} \partial P_{B}}{N_{A} \partial P_{A}+N_{B} \partial P_{B}}+\left(q^{G T}-q^{*}\right) \Delta^{\prime}\left(q^{G T}\right) \\
& \approx \frac{u \delta N_{B} \partial P_{B}}{N_{A} \partial P_{A}+N_{B} \partial P_{B}}
\end{aligned}
$$

assuming that the marginal cost of an additional student is fixed.

The first term of the Equation 3 can be written as:

$$
\begin{aligned}
q^{*} \nu_{A}\left(\theta_{0}^{*}, z_{0}\right)-q^{G T} \nu_{A}\left(\theta_{0}^{G T}, z_{0}\right) & =q^{*}\left(\theta_{0}^{*}-\theta_{0}^{G T}\right) \nu\left(\theta_{0}^{G T}, z_{0}\right)+\left(q^{*}-q^{G T}\right) \nu\left(\theta_{0}^{G T}, z_{0}\right) \\
& =-q^{*} \frac{u \delta N_{B} \partial P_{B}}{N_{A} \partial P_{A}+N_{B} \partial P_{B}} \nu\left(\theta_{0}^{G T}, z_{0}\right)+\left(q^{*}-q^{G T}\right) \nu\left(\theta_{0}^{G T}, z_{0}\right) .
\end{aligned}
$$


Consider now the second term:

$$
\begin{aligned}
N_{B} P_{B}\left(\nu_{A}\left(\theta_{0}^{*}+u \delta, z_{0}\right)-\nu_{A}\left(\theta_{0}^{G T}, z_{0}\right)\right) & =N_{B} P_{B}\left(\theta_{0}^{*}+u \delta-\theta^{G T}\right) \partial \nu\left(\theta_{0}^{G T}, z_{0}\right) \\
& =N_{B} P_{B} u \delta \frac{N_{A} \partial P_{A}-N_{B} \partial P_{B}}{N_{A} \partial P_{A}+N_{B} \partial P_{B}} \partial \nu\left(\theta_{0}^{G T}, z_{0}\right) .
\end{aligned}
$$

The evolution of the global talent is then

$$
\begin{aligned}
& q \nu_{A}\left(\theta_{0}^{*}, z_{0}\right)+N_{B} P_{B}\left(\nu_{B}\left(\theta_{0}^{*}, z_{0}\right)-\nu_{A}\left(\theta_{0}^{*}, z_{0}\right)\right)-q^{G T} \nu\left(\theta_{0}^{G T}, z_{0}\right) \\
& =\frac{q^{*}\left(u \delta N_{B} \partial P_{B}\right) \nu\left(\theta_{0}^{G T}, z_{0}\right)+N_{B} P_{B} u \delta\left(N_{A} \partial P_{A}-N_{B} \partial P_{B}\right) \partial \nu\left(\theta_{0}^{G T}, z_{0}\right)}{N_{A} \partial P_{A}+N_{B} \partial P_{B}}+\left(q^{*}-q^{G T}\right) \nu\left(\theta_{0}^{G T}, z_{0}\right)
\end{aligned}
$$

\section{B The effect of heterogeneity on the optimal tu- ition fees}

Let us simplify the term relating to population heterogeneity:

$$
\frac{\partial\left(N_{A} P_{A} \nu_{A}+N_{B} P_{B} \nu_{B}\right)}{\partial\left(N_{A} P_{A}+N_{B} P_{B}\right)}
$$

The denominator is $N_{A} \partial P_{A}+N_{B} \partial P_{B}$. For the numerator, note that

$$
P_{A} \nu_{A}=\mathbb{P}\left(\hat{\theta}_{A} \geq \theta_{0}, z \geq z_{0}\right) \mathbb{E}\left[\theta \mid \hat{\theta}_{A} \geq \theta_{0}, z \geq z_{0}\right]=\int \theta \mathbb{1}_{\theta \geq \theta_{0}, z \geq z_{0}} f_{\hat{\theta}_{A}}(\theta) d \theta
$$

Differentiating with respect to $\theta_{0}$ :

$$
\begin{aligned}
\partial P_{A} \nu_{A} & =-\int \theta \mathbb{1}_{\theta=\theta_{0}, z \geq z_{0}} f_{\hat{\theta}_{A}}(\theta) d \theta \\
& =-\mathbb{E}\left[\theta \mid \hat{\theta}_{A}=\theta_{0}, z \geq z_{0}\right] \mathbb{P}\left(\hat{\theta}_{A}=\theta_{0}, z \geq z_{0}\right) \\
& =\mathbb{E}\left[\theta \mid \hat{\theta}_{A}=\theta_{0}, z \geq z_{0}\right] \partial P_{A}
\end{aligned}
$$

The same calculation leads to

$$
\partial P_{B} \nu_{B}=\mathbb{E}\left[\theta \mid \hat{\theta}_{B}=\theta_{0}, z \geq z_{0}\right] \partial P_{B}
$$

Since $\hat{\theta}_{A}$ is unbiased,

$$
\mathbb{E}\left[\theta \mid \hat{\theta}_{A}=\theta_{0}, z \geq z_{0}\right]=\theta_{0} \text { and } \partial P_{A} \nu_{A}=\theta_{0} \partial P_{A} .
$$

However, $\hat{\theta}_{B}$ has a non null bias equal to $-u \delta$, and then

$$
\mathbb{E}\left[\theta \mid \hat{\theta}_{B}=\theta_{0}, z \geq z_{0}\right]=\theta_{0}+u \delta \text { and } \partial P_{B} \nu_{B}=\left(\theta_{0}+u \delta\right) \partial P_{B} .
$$

Finally, we get:

$$
\frac{\partial\left(N_{A} P_{A} \nu_{A}+N_{B} P_{B} \nu_{B}\right)}{N_{A} \partial P_{A}+N_{B} \partial P_{B}}=\frac{N_{A} \theta_{0} \partial P_{A}+N_{B}\left(\theta_{0}+u \delta\right) \partial P_{B}}{N_{A} \partial P_{A}+N_{B} \partial P_{B}}=\theta_{0}+\frac{u \delta N_{B} \partial P_{B}}{N_{A} \partial P_{A}+N_{B} \partial P_{B}}
$$




\section{References}

Philippe Aghion and Patrick Bolton. A theory of trickle-down growth and development. The Review of Economic Studies, 64(2):151-172, 1997.

Charlie L. Baird, Stephanie W. Burge, and John R. Reynolds. Absurdly ambitious? Teenagers' expectations for the future and the realities of social structure. Sociology compass, (2/3):944-962, 2008.

Raymond Boudon. Education, opportunity, and social inequality: Changing prospects in Western society. Wiley-Interscience, New York, 1974.

Raymond Boudon. The art of self-persuasion: The social explanation of false beliefs. Polity Press, Cambridge, 1994.

Pierre Bourdieu. Avenir de classe et causalité du probable. Revue française de sociologie, 15:3-42, 1974.

Richard Breen and John H. Goldthorpe. Explaining educational differentials: Towards a formal rational action theory. Rationality and Society, 9(3):275303, 1997.

Thomas O. Brodaty, Robert J. Gary-Bobo, and Ana Prieto. Heterogeneity in Risk Aversion, Education and Wages. Technical report, Working Paper, TEAM, Université Paris 1, 2009.

Jean-Paul Caillé and Sophie O'Prey. Estime de soi et réussite scolaire sept ans après l'entrée en sixième. Education et formations, (72):25-52, 2005.

Claire Callender. Access to higher education in britain: The impact of tuition fees and financial assistance. Higher education dynamics, 14:105-132, 2006.

S.V. Cameron and J.J. Heckman. The dynamics of educational attainment for black, hispanic, and white males. Journal of Political Economy, 109(3): 455-499, 2001.

Pedro Carneiro and James J. Heckman. The evidence on credit constraints in post-secondary schooling. The Economic Journal, 112(482):705-734, 2002.

Stephen T. Easton and Duane W. Rockerbie. Optimal government subsidies to universities in the face of tuition and enrollment constraints. Education Economics, 16(2):191-201, 2008.

Erica Field. Educational debt burden and career choice: Evidence from a financial aid experiment at nyu law school. American Economic Journal: Applied Economics, 1(1):1-21, 2009.

Ross Finnie, Eric Lascelles, and Aarthur Sweetman. Who goes? the direct and indirect effects of family background on access to post-secondary education. Technical Report 237, Statistics Canada, Ottawa, January 2005. 
Marc Frenette. L'incidence des frais de scolarité sur l'accès à l'université : résultats de la vaste déréglementation des frais de scolarité des programmes professionnels. Technical Report 264, Statistique Canada, Direction des études analytiques, Septembre 2005.

Marc Frenette. Pourquoi les jeunes provenant de familles à plus faible revenu sont-ils moins susceptibles de fréquenter l'université ? analyse fondée sur les aptitudes aux études, l'influence des parents et les contraintes financières. Technical Report 295, Statistique Canada, Ottawa, Février 2007.

Diego Gambetta. Were they pushed or did they jump? - Individual decision mechanisms in education, volume 234. Cambridge University Press, 1987.

Robert J. Gary-Bobo and Alain Trannoy. Faut-il augmenter les droits d'inscription à l'université ? Revue française d'économie, 19(3):189-237, 2005a.

Robert J. Gary-Bobo and Alain Trannoy. Efficient tuition fees, examinations and subsidies. CEPR Discussion paper, 5011, 2005b.

Robert J. Gary-Bobo and Alain Trannoy. Efficient Tuition Fees and Examinations. Journal of the European Economic Association, 6(6):1211-1243, 2008.

Stéphane Gregoir. Les prêts étudiants peuvent-ils être un outil de progrès social ? EDHEC position paper, 2008.

Robert Haveman and Timothy Smeeding. The role of Higher Education in social mobility. The Future of Children, 16(2):125-150, 2006.

Robert Haveman and Barbara Wolfe. The determinants of children's attainments: A review of methods and findings. Journal of Economic Literature, 33(4):1829-1878, 1995.

James C. Hearn. The Relative Roles of Academic, Ascribed, and Socioeconomic Characteristics in College. Sociology of Education, 57(1):22-30, 1984.

James C. Hearn. Academic and nonacademic influences on the college destinations of 1980 high school graduates. Sociology of Education, 64(3):158-171, 1991.

Ana Hidalgo Cabrillana. Endogenous capital market imperfections, human capital, and intergenerational mobility. Journal of Development Economics, 90 (2):285-298, 2009.

Anders Holm and Mads Meier Jaeger. Does relative risk aversion explain educational inequality? a dynamic choice approach. Research in Social Stratification and Mobility, 26(3):199-219, 2008.

Daniel Kahneman, Paul Slovic, and Amos Tversky. Judgment under uncertainty: Heuristics and biases. Cambridge University Press, 1982. 
Michael P. Keane and Kenneth I. Wolpin. The effect of parental transfers and borrowing constraints on educational attainment. International Economic Review, 42(4):1051-1103, 2001.

Benoit Lorel. Higher education system, skill premium and welfare. Education Economics, 17(4):505-522, 2009.

John Micklewright. Choice at sixteen. Economica, 56(221):25-39, 1989.

Erik Plug and Wim Vijverberg. Does family income matter for schooling outcomes? using adoption as a natural experiment. Economic Journal, 115(506): 879-906, 2005.

Thorsten Schneider. Social Inequality in Educational Participation in the German School System in a Longitudinal Perspective: Pathways into and out of the most Prestigious School Track. European Sociological Review, 24(4): 511-526, 2008.

Amartya Sen. Inequality Reexamined. Clarendon Press, 1992.

Alice Sullivan. Students as rational decision-makers: The question of beliefs and attitudes. London Review of Education, 4(3):271-290, 2006.

Herman G. Van de Werfhorst and Saskia Hofstede. Cultural capital or relative risk aversion? Two mechanisms for educational inequality compared1. The British journal of sociology, 58(3):391-415, 2007. 